\title{
Differing severities of acute exacerbations of idiopathic pulmonary fibrosis (IPF): insights from the INPULSIS ${ }^{\circledast}$ trials
}

\author{
Michael Kreuter ${ }^{1 *}$, Harald Koegler ${ }^{2}$, Matthias Trampisch², Silke Geier ${ }^{2}$ and Luca Richeldi ${ }^{3}$
}

\begin{abstract}
Background: Given the broad definition of an acute exacerbation of IPF, it is likely that acute exacerbations are heterogeneous in their aetiology, severity and clinical course. We used pooled data from the INPULSIS ${ }^{\oplus}$ trials of nintedanib versus placebo to investigate whether acute exacerbations reported as serious adverse events were associated with higher mortality than those reported as non-serious adverse events and to assess the effect of nintedanib on these types of events.
\end{abstract}

Methods: Adverse events considered by an investigator to be an acute exacerbation were adjudicated as a confirmed acute exacerbation, suspected acute exacerbation, or not an acute exacerbation. Time to first investigator-reported acute exacerbation or confirmed/suspected acute exacerbation reported as a serious adverse event or non-serious adverse event over the 52-week treatment period was assessed post-hoc. Deaths were assessed based on data collected over the 52-week treatment period.

Results: Of 63 patients who had $\geq 1$ investigator-reported acute exacerbation, 48 (76.2\%) had a first acute exacerbation reported as a serious adverse event. Thirty-six (3.4\%) patients had $\geq 1$ confirmed/suspected acute exacerbation, of whom 31 had a first event reported as a serious adverse event. Investigator-reported acute exacerbations reported as serious adverse events occurred in 23 patients in the nintedanib group and 26 in the placebo group. Confirmed/suspected acute exacerbations reported as serious adverse events occurred in 10 and 21 patients in these groups, respectively. Nintedanib significantly reduced the risk of a first acute exacerbation reported as a serious adverse event (HR 0.57 [95\% Cl: 0.32, 0.99]; $p=0.0476$ ) and the risk of a first confirmed/suspected acute exacerbation reported as a serious adverse event (HR 0.30 [95\% Cl: 0.14, 0.64]; $p=0.0019$ ) versus placebo. A higher proportion of patients with investigator-reported acute exacerbations reported as serious adverse events died than patients with acute exacerbations reported as non-serious adverse events (61.2\% versus $7.1 \%$ ).

Conclusion: Different severities of acute exacerbation of IPF may exist. Acute exacerbations reported as serious adverse events in the INPULSIS ${ }^{\oplus}$ trials were associated with high mortality. Nintedanib significantly reduced the risk of acute exacerbations reported as serious adverse events.

Trial registration: ClinicalTrials.gov NCT01335464 and NCT01335477.

Keywords: Nintedanib, Tyrosine kinase inhibitor, Serious adverse events, Disease progression, Treatment outcome

\footnotetext{
* Correspondence: kreuter@uni-heidelberg.de

${ }^{1}$ Center for Interstitial and Rare Lung Diseases, Pneumology and Respiratory

Care Medicine, Thoraxklinik, University of Heidelberg, Röntgenstraße 1, 69120

Heidelberg, Germany

Full list of author information is available at the end of the article
}

(c) The Author(s). 2019 Open Access This article is distributed under the terms of the Creative Commons Attribution 4.0 International License (http://creativecommons.org/licenses/by/4.0/), which permits unrestricted use, distribution, and reproduction in any medium, provided you give appropriate credit to the original author(s) and the source, provide a link to the Creative Commons license, and indicate if changes were made. The Creative Commons Public Domain Dedication waiver (http://creativecommons.org/publicdomain/zero/1.0/) applies to the data made available in this article, unless otherwise stated. 


\section{Introduction}

Idiopathic pulmonary fibrosis (IPF) is a chronic progressive fibrosing interstitial lung disease characterised by loss of lung function [1]. IPF has a variable and unpredictable clinical course [2]. Many patients experience acute deteriorations in lung function known as acute exacerbations, which are associated with very high morbidity and mortality [3]. A perspective published by an international group of experts in 2007 defined acute exacerbations of IPF as acute deteriorations in respiratory symptoms associated with changes in radiographical appearance and the absence of an identifiable cause [4]. In 2016, an international working group proposed that the requirement for an event to be idiopathic be removed from the definition of an acute exacerbation of IPF based on recognition that there is little clinical or biological rationale for distinguishing idiopathic from non-idiopathic events [3].

The reported frequency of acute exacerbations in patients with IPF varies widely depending on the methodology used. In clinical trials conducted in patients with IPF and mild to moderate impairment in lung function at baseline, acute exacerbations were reported in 2 to $16 \%$ of placebo-treated patients over 24 to 60 weeks [517]. Similar or slightly higher frequencies of acute exacerbations have been observed in contemporary cohort studies [18-21].

Given the broad definition of an acute exacerbation of IPF, it is likely that events classified as acute exacerbations of IPF are heterogeneous in their aetiology, severity, and clinical course. A clinical trial, in which adverse event reporting rules provide a definition for a serious adverse event, represents an opportunity to assess the clinical impact of acute exacerbations based on their seriousness. In this analysis, we used data from the Phase III INPULSIS ${ }^{\circledR}$ trials of nintedanib in patients with IPF to investigate whether acute exacerbations reported as serious adverse events were associated with higher mortality than events reported as non-serious adverse events and to assess the effect of nintedanib on these events.

\section{Methods}

The design of the two replicate INPULSIS ${ }^{\oplus}$ trials has been described [17]. Briefly, patients aged $\geq 40$ years with a diagnosis of IPF within the previous 5 years, forced vital capacity $(\mathrm{FVC}) \geq 50 \%$ predicted, diffusing capacity of the lung for carbon monoxide (DLco) 30-79\% predicted and a forced expiratory volume in $1 \mathrm{~s} / \mathrm{FVC}$ ratio $\geq$ 0.7 were randomised 3:2 to receive nintedanib $150 \mathrm{mg}$ twice daily or placebo for 52 weeks, with a follow-up visit 4 weeks after the last dose of trial medication. The primary endpoint was the annual rate of decline in FVC (mL/year). Time to first investigator-reported acute exacerbation over the 52-week treatment period was a key secondary endpoint. Acute exacerbations were defined in the trial protocol as events meeting all of the following criteria: worsening/development of dyspnoea within 30 days; new diffuse pulmonary infiltrates on chest X-ray and/or high-resolution computed tomography parenchymal abnormalities with no pneumothorax or pleural effusion (new ground-glass opacities) since last visit; and exclusion of known causes of acute worsening, including infection, left heart failure, and pulmonary embolism, as per routine clinical practice and microbiological studies. Adverse events considered by an investigator to be acute exacerbations were adjudicated by a committee of three experts blinded to treatment assignment as a confirmed acute exacerbation (if all protocol-defined criteria were met), a suspected acute exacerbation (if the event was felt to be an acute exacerbation but did not meet all protocol-specified criteria), or not an acute exacerbation (if an alternative cause was identified) [22].

Adverse events were reported by the investigators from randomisation to 4 weeks after the last dose of trial medication. Serious adverse events were defined as events that resulted in death, were immediately life-threatening, resulted in persistent or clinically significant disability/incapacity, required/prolonged hospitalisation, were related to a congenital anomaly or birth defect, or were deemed serious for any other reason.

We conducted a post-hoc analysis of time to first acute exacerbation reported as a serious adverse event or non-serious adverse event over the 52-week treatment period using pooled data from both INPULSIS ${ }^{\odot}$ trials. Hazard ratios (HR) and two-sided $p$-values were calculated using Cox's regression models with terms for trial, treatment, sex, age, height. Baseline characteristics of patients with $\geq 1$ investigator-reported acute exacerbation reported as a serious adverse event versus patients who did not have an acute exacerbation were compared using t-test (continuous variables) or chi-square test (categorical variables). Deaths were based on data collected over the 52-week treatment period.

\section{Results}

A total of 1061 patients were treated in the INPULSIS trials (638 with nintedanib, 423 with placebo). At baseline, mean FVC was $80 \%$ predicted and mean DLco was $47 \%$ predicted. The majority of patients were male (79\%) and former smokers (68\%).

Over 52 weeks, $63(5.9 \%)$ patients had $\geq 1$ investigator-reported acute exacerbation, of whom 48 (76.2\%) had a first acute exacerbation reported as a serious adverse event (Table 1). Of these 48 events, 20 had fatality noted as the reason for the event being regarded as a serious adverse event. One patient had an acute 
Table 1 Acute exacerbations in the INPULSIS ${ }^{\oplus}$ trials

\begin{tabular}{llll}
\hline & \multicolumn{2}{l}{ Adjudication result } & Total \\
\cline { 2 - 3 } Adverse event category & $\begin{array}{l}\text { Confirmed/ } \\
\text { suspected } \\
\text { acute } \\
\text { exacerbation }\end{array}$ & $\begin{array}{l}\text { Not an } \\
\text { acute } \\
\text { exacerbation }\end{array}$ & \\
\hline Serious adverse event & 31 & 18 & $49^{*}$ \\
Non-serious adverse event & 5 & 9 & $14^{*}$ \\
Total & 36 & 27 & 63 \\
\hline
\end{tabular}

*One patient had an acute exacerbation reported as a non-serious adverse event followed by an acute exacerbation reported as a serious adverse event. In subsequent analyses, this patient was classified according to his worse event

exacerbation reported as a non-serious adverse event followed by an acute exacerbation reported as a serious adverse event; in subsequent analyses, this patient was classified according to his worse event. Thirty-six (3.4\%) patients had $\geq 1$ adjudicated confirmed/suspected acute exacerbation, of whom 31 had a first event reported as a serious adverse event. Twenty-seven (2.5\%) patients had an acute respiratory worsening adjudicated as not an acute exacerbation, of whom 18 had a first event reported as a serious adverse event.

Patients with $\geq 1$ investigator-reported acute exacerbation reported as a serious adverse event had significantly lower FVC and DLco and higher (worse) St George's Respiratory Questionnaire (SGRQ) total score, composite physiological index and Gender-Age-Physiology (GAP) stage at baseline than patients who did not have an investigator-reported acute exacerbation (Table 2).

Deaths occurred in a higher proportion of patients with investigator-reported acute exacerbations reported as serious adverse events $(n=30,61.2 \%)$ than patients with acute exacerbations reported as non-serious

Table 2 Baseline characteristics by acute exacerbation reported in INPULSIS ${ }^{\oplus}$ trials (mean \pm SD or $n$ \%)

\begin{tabular}{|c|c|c|c|c|}
\hline & $\begin{array}{l}\text { Patients who did } \\
\text { not have an acute } \\
\text { exacerbation ( } n= \\
\text { 998) }\end{array}$ & $\begin{array}{l}\text { Patients who had } \geq 1 \\
\text { acute exacerbation } \\
\text { reported as a serious } \\
\text { adverse event }(n=49)\end{array}$ & $\begin{array}{l}\text { Patients who had } \geq 1 \text { acute } \\
\text { exacerbation but none } \\
\text { reported as a serious adverse } \\
\text { event }(n=14)\end{array}$ & $\begin{array}{l}p \text { value for patients who did not have an } \\
\text { acute exacerbation vs patients who had } \geq 1 \\
\text { acute exacerbation reported as a serious } \\
\text { adverse event }\end{array}$ \\
\hline Male & $789(79.1)$ & $43(87.8)$ & $9(64.3)$ & n.s. \\
\hline Age, years & $66.6 \pm 8.0$ & $69.1 \pm 7.8$ & $69.8 \pm 6.7$ & n.s. \\
\hline $\begin{array}{l}\text { Body mass index, kg/ } \\
\mathrm{m}^{2}\end{array}$ & $28.0 \pm 4.6$ & $27.0 \pm 4.1$ & $27.2 \pm 4.2$ & n.s. \\
\hline Ex/current smoker & $717(71.8)$ & $39(79.6)$ & $9(64.3)$ & n.s. \\
\hline $\begin{array}{l}\text { Centrilobular } \\
\text { emphysema* }\end{array}$ & $401(40.2)$ & $17(34.7)$ & $2(14.3)$ & n.s. \\
\hline $\begin{array}{l}\text { Time since diagnosis, } \\
\text { years }\end{array}$ & $1.6 \pm 1.3$ & $1.8 \pm 1.5$ & $1.9 \pm 1.3$ & n.s. \\
\hline $\mathrm{FVC}, \mathrm{mL}$ & $2746 \pm 780$ & $2372 \pm 628$ & $2057 \pm 549$ & 0.001 \\
\hline FVC, \% predicted & $80.2 \pm 17.8$ & $71.5 \pm 15.9$ & $62.0 \pm 7.9$ & 0.0008 \\
\hline $\begin{array}{l}\text { Diffusing capacity of } \\
\text { the lung for carbon } \\
\text { monoxide }{ }^{\dagger}, \mathrm{mmol} / \\
\mathrm{min} / \mathrm{kPa}\end{array}$ & $3.9 \pm 1.2$ & $3.4 \pm 1.3$ & $3.3 \pm 1.0$ & 0.0074 \\
\hline $\begin{array}{l}\text { St. George's } \\
\text { Respiratory } \\
\text { Questionnaire total } \\
\text { score }\end{array}$ & $38.9 \pm 18.8$ & $50.6 \pm 17.9$ & $45.3 \pm 18.2$ & $<0.0001$ \\
\hline $\begin{array}{l}\text { Composite } \\
\text { physiological index }\end{array}$ & $45.7 \pm 10.8$ & $51.3 \pm 11.8$ & $54.9 \pm 8.3$ & 0.0004 \\
\hline GAP score & $3.5 \pm 1.3$ & $4.2 \pm 1.3$ & $4.6 \pm 1.0$ & 0.0002 \\
\hline \multicolumn{5}{|l|}{ HRCT assessment" } \\
\hline $\begin{array}{l}\text { Criteria A, B and C } \\
\text { met }\end{array}$ & $432(43.3)$ & $25(51.0)$ & $6(42.9)$ & n.s. \\
\hline $\begin{array}{l}\text { Criteria A and C } \\
\text { met }\end{array}$ & $99(9.9)$ & $5(10.2)$ & $0(0.0)$ & n.s. \\
\hline $\begin{array}{l}\text { Criteria B and C } \\
\text { met }\end{array}$ & $442(44.3)$ & 19 (38.8) & $7(50.0)$ & n.s. \\
\hline
\end{tabular}

${ }^{*}$ Based on qualitative assessment of HRCT scans, centrally reviewed by a single radiologist. ${ }^{\dagger}$ Haemoglobin-corrected. ${ }^{\ddagger}$ As described in [28]. ${ }^{5}$ As described in [29]. "A: definite honeycomb lung destruction with basal and peripheral predominance; B: presence of reticular abnormality and traction bronchiectasis consistent with fibrosis with basal and peripheral predominance; C: absence of atypical features, specifically nodules and consolidation, with ground glass opacity, if present, less extensive than reticular opacity pattern. n.s., not significant 
adverse events $(n=1 ; 7.1 \%)$ or patients who did not have an acute exacerbation $(n=43 ; 4.3 \%)$. There was a significant difference in the risk of death between patients with acute exacerbations reported as serious adverse events and patients who did not have an acute exacerbation (HR 53.6 [95\% CI: 32.1, 89.5]; $p<0.001$ ) and a numerical, but not statistically significant, difference in the risk of death between patients with acute exacerbations reported as non-serious adverse events and patients who did not have an acute exacerbation (HR 3.7 [95\% CI: 0.5, 27.2]; $p=0.1962$ ) (Fig. 1).

Investigator-reported acute exacerbations reported as serious adverse events occurred in $23(3.6 \%)$ versus $26(6.1 \%)$ patients in the nintedanib and placebo groups, respectively. Of these patients, 13 (56.5\%) in the nintedanib group and $17(65.4 \%)$ in the placebo group died. Investigator-reported acute exacerbations reported as non-serious adverse events occurred in 8 $(1.3 \%)$ versus $6(1.4 \%)$ patients in the nintedanib and placebo groups, respectively. Of these, no patients in the nintedanib group and 1 patient in the placebo group died.

Confirmed/suspected acute exacerbations reported as serious adverse events occurred in $10(1.6 \%)$ versus 21
(5.0\%) patients in the nintedanib and placebo groups, respectively. Of these patients, $5(50.0 \%)$ in the nintedanib group and $14(66.7 \%)$ in the placebo group died. Confirmed/suspected acute exacerbations reported as non-serious adverse events occurred in $2(0.3 \%)$ versus 3 $(0.7 \%)$ patients in the nintedanib and placebo groups, respectively. Of these, no patients in the nintedanib group and 1 patient in the placebo group died.

Compared to placebo, nintedanib significantly reduced the risk of a first acute exacerbation reported as a serious adverse event (HR 0.57 [95\% CI: 0.32, 0.99]; $p=$ 0.0476 ) and the risk of a first confirmed/suspected acute exacerbation reported as a serious adverse event (HR 0.30 [95\% CI: 0.14, 0.64]; $p=0.0019$ ) (Fig. 2).

\section{Discussion}

Acute exacerbations in patients with IPF are known to be associated with high mortality [3]. A retrospective review of clinical records from 553 patients with IPF in Japan from 2003 to 2007 found that acute exacerbation was the cause of death in $40 \%$ of patients [23]. Previous analyses of data from the INPULSIS ${ }^{\circ}$ trials have shown that the mortality rate following an investigator-reported acute exacerbation in placebo-treated patients was $40 \%$

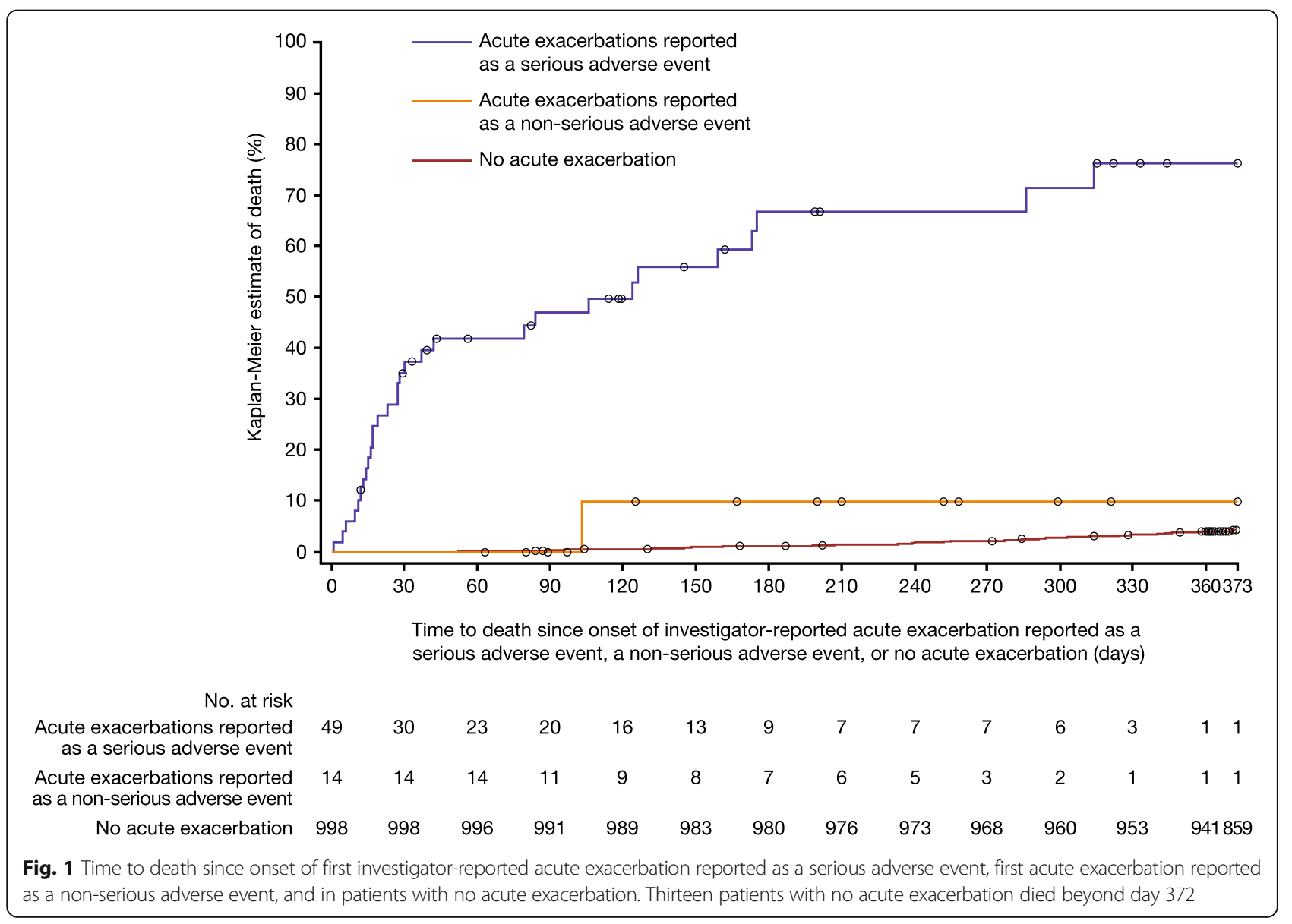




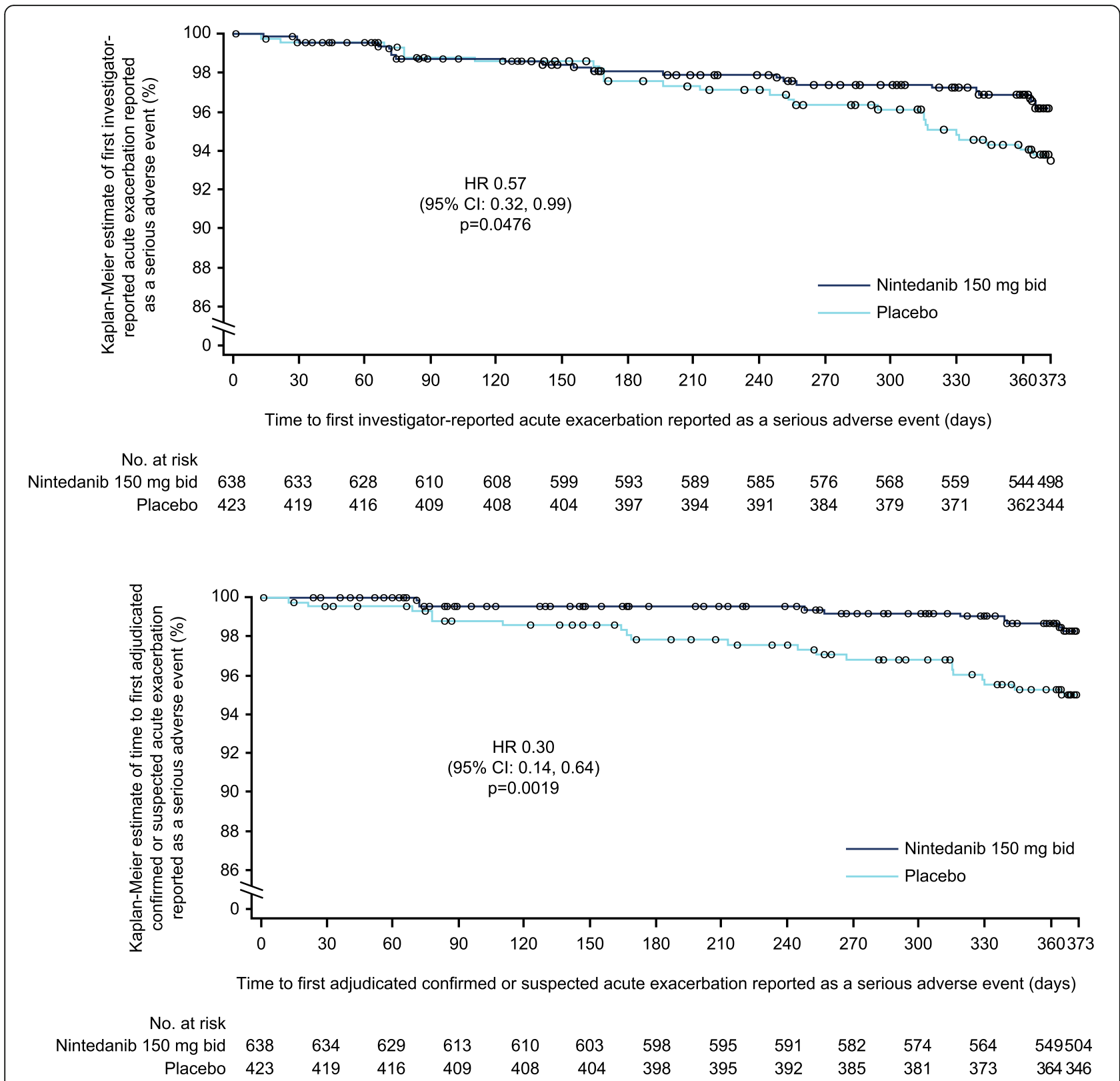

Fig. 2 Time to (a) first investigator-reported and (b) adjudicated confirmed or suspected acute exacerbation reported as a serious adverse event in patients treated with nintedanib or placebo

after 30 days and $57 \%$ after 180 days and that mortality following investigator-reported acute exacerbations and adjudicated confirmed/suspected acute exacerbations was similar [22]. In these new analyses, we demonstrated that acute exacerbations reported as serious adverse events are, regardless of adjudication, associated with particularly high mortality, with $61 \%$ of patients who had such an event dying within the 52-week treatment period. This suggests that while all acute exacerbations are clinically significant events, some types of acute exacerbations, possibly those with specific aetiologies or those that affect patients with certain clinical characteristics, might have a particularly adverse impact on prognosis.

Patients who had acute exacerbations reported as serious adverse events had more severe functional impairment at baseline than patients who did not have an acute exacerbation. This is in line with previous analyses of risk factors for acute exacerbations, which have consistently found a higher rate of acute 
exacerbations in patients with lower FVC at baseline [21, 22, 24, 25], and supports the concept of acute exacerbations as clinical events triggered by injury or stress to the lung that are more likely to manifest in patients with advanced disease [3].

Nintedanib is an intracellular inhibitor of tyrosine kinases that has been shown to inhibit processes fundamental to the pathogenesis of IPF [26]. In clinical trials, nintedanib reduced disease progression in patients with IPF by reducing the rate of decline in FVC by about $50 \%$, irrespective of FVC at baseline [16, 17, 27]. Pooled data from the INPULSIS $^{\circ}$ trials showed that investigator-reported acute exacerbations were reported in 4.9 and $7.6 \%$ of patients treated with nintedanib and placebo, respectively (HR 0.64 [95\% CI: 0.39, 1.05]; $p=$ 0.08 ) and confirmed/suspected acute exacerbations in 1.9 and $5.7 \%$ of patients treated with nintedanib and placebo, respectively (HR 0.32 [95\% CI: $0.16,0.65$ ]; $p=$ 0.001) [17]. A further post-hoc analysis suggested that mortality following investigator-reported acute exacerbations and confirmed/suspected acute exacerbations was lower in patients treated with nintedanib than placebo (HR 0.56 [95\% CI: 0.28, 1.11]; $p=0.092$ and HR 0.57 [95\% CI: $0.22,1.48 ; p=0.24$, respectively) [22].

Limitations of our analyses include their post-hoc nature, the small number of events, and the fact that events that resulted in death should, by definition, have been reported as serious adverse events. We were unable to determine the reasons why some events that were reported as acute exacerbations were not reported as serious adverse events, particularly when all events that resulted in hospitalization were to be reported as serious adverse events. Although acute exacerbations that were reported as serious adverse events were associated with particularly high mortality, it is unknown whether these events were also associated with other indicators of severity such as treatment in intensive care.

\section{Conclusions}

Our analysis of data from the Phase III INPULSIS ${ }^{\circ}$ trials of nintedanib in patients with IPF showed that acute exacerbations reported as serious adverse events were associated with higher mortality than events reported as non-serious adverse events. Nintedanib significantly reduced the risk of acute exacerbations reported as serious adverse events. Further research is needed into the causes of acute exacerbations in patients with IPF and how their risk and impact can be reduced. A severity grading might aid clinicians in making decisions about how to manage acute exacerbations in patients with IPF.

\section{Abbreviations}

DLco: Diffusing capacity of the lung for carbon monoxide; FVC: Forced vital capacity; GAP: Gender-Age-Physiology; HR: Hazard ratio; IPF: Idiopathic pulmonary fibrosis; SGRQ: St George's Respiratory Questionnaire

\section{Acknowledgements}

Medical writing assistance, supported financially by Boehringer Ingelheim, was provided by Julie Fleming and Wendy Morris of FleishmanHillard Fishburn, London, UK, during the preparation of this article. The authors were fully responsible for all content and editorial decisions, were involved at all stages of manuscript development, and have approved the final version of the manuscript, which reflects the authors' interpretation and conclusions.

\section{Funding}

The INPULSIS ${ }^{\oplus}$ trials were funded by Boehringer Ingelheim.

\section{Availability of data and materials}

The datasets used for the current study are available from the authors on reasonable request.

\section{Author's contributions}

The authors contributed to the writing and critical review of this manuscript and have approved the final version of the manuscript.

\section{Ethics approval and consent to participate}

The INPULSIS ${ }^{\oplus}$ trials were conducted in accordance with the principles of the Declaration of Helsinki and the Harmonized Tripartite Guideline for Good Clinical Practice from the International Conference on Harmonization and were approved by local authorities. The clinical protocol was approved by an independent ethics committee or institutional review board at each participating centre. All patients provided written informed consent before study entry.

\section{Consent for publication}

Not applicable.

\section{Competing interests}

HK, MT, SG are employees of Boehringer Ingelheim. LR reports grants and personal fees from InterMune, and personal fees from Boehringer Ingelheim, Biogen, Cipla, ImmuneWorks, Medlmmune, Pliant Therapeutics, Roche, Sanofi-Aventis, Shionogi, and Takeda. MK and his institution received grants and reimbursement for speakers bureaus and consulting from Boehringer Ingelheim and Roche and fees for consulting from Galapagos.

\section{Publisher's Note}

Springer Nature remains neutral with regard to jurisdictional claims in published maps and institutional affiliations.

\section{Author details}

${ }^{1}$ Center for Interstitial and Rare Lung Diseases, Pneumology and Respiratory Care Medicine, Thoraxklinik, University of Heidelberg, Röntgenstraße 1, 69120 Heidelberg, Germany. ${ }^{2}$ Boehringer Ingelheim International $\mathrm{GmbH}$, Ingelheim am Rhein, Germany. ${ }^{3}$ Università Cattolica del Sacro Cuore, Fondazione Policlinico A. Gemelli, Rome, Italy.

Received: 17 May 2018 Accepted: 28 March 2019

Published online: 11 April 2019

\section{References}

1. Raghu G, Collard HR, Egan JJ, Martinez FJ, Behr J, Brown KK, et al. An official ATS/ERS/JRS/ALAT statement: idiopathic pulmonary fibrosis: evidence-based guidelines for diagnosis and management. Am J Respir Crit Care Med. 2011; 183:788-824.

2. Kim HJ, Perlman D, Tomic R. Natural history of idiopathic pulmonary fibrosis. Respir Med. 2015;109:661-70.

3. Collard HR, Ryerson CJ, Corte TJ, Jenkins G, Kondoh Y, Lederer DJ, et al. Acute exacerbation of idiopathic pulmonary fibrosis. An international working group report. Am J Respir Crit Care Med. 2016;194:265-75.

4. Collard HR, Moore BB, Flaherty KR, Brown KK, Kaner RJ, King TE Jr, et al. Acute exacerbations of idiopathic pulmonary fibrosis. Am J Respir Crit Care Med. 2007;176:636-43.

5. Daniels CE, Lasky JA, Limper AH, Mieras K, Gabor E, Schroeder DR, et al. Imatinib treatment for idiopathic pulmonary fibrosis: randomized placebocontrolled trial results. Am J Respir Crit Care Med. 2010;181:604-10. 
6. Idiopathic Pulmonary Fibrosis Clinical Research Network, Martinez FJ, de Andrade JA, Anstrom KJ, King TE Jr, Raghu G. Randomized trial of acetylcysteine in idiopathic pulmonary fibrosis. N Engl J Med. 2014;370: 2093-101.

7. King TE Jr, Behr J, Brown KK, du Bois RM, Lancaster L, de Andrade JA, et al. BUILD-1: a randomized placebo-controlled trial of bosentan in idiopathic pulmonary fibrosis. Am J Respir Crit Care Med. 2008;177:75-81.

8. King TE Jr, Albera C, Bradford WZ, Costabel U, Hormel P, Lancaster L, et al. Effect of interferon gamma-1b on survival in patients with idiopathic pulmonary fibrosis (INSPIRE): a multicentre, randomised, placebo-controlled trial. Lancet. 2009;374:222-8.

9. King TE Jr, Brown KK, Raghu G, et al. BUILD-3: a randomized, controlled trial of bosentan in idiopathic pulmonary fibrosis. Am J Respir Crit Care Med. 2011;184:92-9

10. King TE Jr, Bradford WZ, Castro-Bernardini S, Fagan EA, Glaspole I, Glassberg MK, et al. A phase 3 trial of pirfenidone in patients with idiopathic pulmonary fibrosis. N Engl J Med. 2014;370:2083-92.

11. Noble PW, Albera C, Bradford WZ, Costabel U, Glassberg MK, Kardatzke D, et al. Pirfenidone in patients with idiopathic pulmonary fibrosis (CAPACITY): two randomised trials. Lancet. 2011;377:1760-9.

12. Noth I, Anstrom KJ, Calvert SB, de Andrade J, Flaherty KR, Glazer C, et al. A placebo-controlled randomized trial of warfarin in idiopathic pulmonary fibrosis. Am J Respir Crit Care Med. 2012;186:88-95.

13. Raghu G, Brown KK, Costabel U, Cottin V, du Bois RM, Lasky JA, et al. Treatment of idiopathic pulmonary fibrosis with etanercept: an exploratory, placebo-controlled trial. Am J Respir Crit Care Med. 2008; 178:948-55.

14. Raghu G, Million-Rousseau R, Morganti A, Perchenet L, Behr J, MUSIC Study Group. Macitentan for the treatment of idiopathic pulmonary fibrosis: the randomised controlled MUSIC trial. Eur Respir J. 2013;42:1622-32.

15. Raghu G, Behr J, Brown KK, Egan JJ, Kawut SM, Flaherty KR, et al. Treatment of idiopathic pulmonary fibrosis with ambrisentan: a parallel, randomized trial. Ann Intern Med. 2013;158:641-9.

16. Richeldi L, Costabel U, Selman M, Kim DS, Hansell DM, Nicholson AG, et al. Efficacy of a tyrosine kinase inhibitor in idiopathic pulmonary fibrosis. N Engl J Med. 2011;365:1079-87.

17. Richeldi L, du Bois RM, Raghu G, Azuma A, Brown KK, Costabel U, et al. Efficacy and safety of nintedanib in idiopathic pulmonary fibrosis. N Engl J Med. 2014;370:2071-82.

18. Johannson KA, Vittinghoff E, Lee K, Balmes JR, Ji W, Kaplan GG, et al. Acute exacerbation of idiopathic pulmonary fibrosis associated with air pollution exposure. Eur Respir J. 2014;43:1124-31.

19. Mura M, Porretta MA, Bargagli E, Sergiacomi G, Zompatori M, Sverzellati N, et al. Predicting survival in newly diagnosed idiopathic pulmonary fibrosis: a 3-year prospective study. Eur Respir J. 2012;40:101-9.

20. Ohshimo S, Ishikawa N, Horimasu Y, Hattori N, Hirohashi N, Tanigawa K, et al. Baseline KL-6 predicts increased risk for acute exacerbation of idiopathic pulmonary fibrosis. Respir Med. 2014;108:1031-9.

21. Song JW, Hong SB, Lim CM, Koh Y, Kim DS. Acute exacerbation of idiopathic pulmonary fibrosis: incidence, risk factors and outcome. Eur Respir J. 2011:37:356-63.

22. Collard HR, Richeldi L, Kim DS, Taniguchi H, Tschoepe I, Luisetti M, et al. Acute exacerbations in the INPULSIS trials of nintedanib in idiopathic pulmonary fibrosis. Eur Respir J. 2017;19:49.

23. Natsuizaka M, Chiba H, Kuronuma K, Otsuka M, Kudo K, Mori M, et al. Epidemiologic survey of Japanese patients with idiopathic pulmonary fibrosis and investigation of ethnic differences. Am J Respir Crit Care Med. 2014;190:773-9

24. Kondoh Y, Taniguchi $\mathrm{H}$, Katsuta T, Kataoka K, Kimura T, Nishiyama O, et al. Risk factors of acute exacerbation of idiopathic pulmonary fibrosis. Sarcoidosis Vasc Diffuse Lung Dis. 2010;27:103-10.

25. Collard HR, Yow E, Richeldi L, Anstrom K, Glazer C, investigators IPF. Suspected acute exacerbation of idiopathic pulmonary fibrosis as an outcome measure in clinical trials. Respir Res. 2013;14:73.

26. Wollin L, Wex E, Pautsch A, Schnapp G, Hostettler KE, Stowasser S, et al. Mode of action of nintedanib in the treatment of idiopathic pulmonary fibrosis. Eur Respir J. 2015;45:1434-45.

27. Costabel U, Inoue Y, Richeldi L, Collard HR, Tschoepe I, Stowasser S, et al. Efficacy of nintedanib in idiopathic pulmonary fibrosis across prespecified subgroups in INPULSIS. Am J Respir Crit Care Med. 2016; 193:178-85.
28. Wells AU, Desai SR, Rubens MB, Goh NS, Cramer D, Nicholson AG, et al. Idiopathic pulmonary fibrosis: a composite physiologic index derived from disease extent observed by computed tomography. Am J Respir Crit Care Med. 2003;167:962-9.

29. Ley B, Ryerson CJ, Vittinghoff E, Ryu JH, Tomassetti S, Lee JS, et al. A multidimensional index and staging system for idiopathic pulmonary fibrosis. Ann Intern Med. 2012;156:684-91.

\section{Ready to submit your research? Choose BMC and benefit from:}

- fast, convenient online submission

- thorough peer review by experienced researchers in your field

- rapid publication on acceptance

- support for research data, including large and complex data types

- gold Open Access which fosters wider collaboration and increased citations

- maximum visibility for your research: over $100 \mathrm{M}$ website views per year

At BMC, research is always in progress.

Learn more biomedcentral.com/submissions 